\title{
New bis(15-Crown-5) derivatives and their physicochemical properties
}

\author{
Piotr Kuś \\ Department of Chemistry, University of Silesia, 9, Szkolna Street, 40-006 Katowice, Poland \\ E-mail:pkus@ich.us.edu.pl
}

Dedicated to Professor Richard A. Bartsch on the occasion of his $\mathbf{7 0}^{\text {th }}$ birthday

DOI: http://dx.doi.org/10.3998/ark.5550190.0011.705

\begin{abstract}
Two novel bis-crown ethers $\mathbf{1}$ and $\mathbf{2}$ were obtained. Both compounds form complexes with alkali metal ions. Such formation process was investigated using mass spectrometry (ESI MS). Compounds 1 and $\mathbf{2}$ can form both mono- and bimetallic complexes. Detected also are ions that reflect formation of complexes between two molecules of bis-crown ethers and one metal ion. Cesium and rubidium ions form with compound 2 only complexes of 1:1 type.
\end{abstract}

Keywords: Crown ethers, bis(crown ethers), mass spectroscopy, ESI MS, metal complexes

\section{Introduction}

It is somewhat difficult to enumerate all practical applications of crown-ethers, not only chemical ones but also in various areas of material sciences. The diversity of crown ethers and their sheer number reflect their popularity in contemporary chemistry. Bis(crown-ethers) and their applications have been widely described in the literature ${ }^{1-3}$. The first compounds of this type appeared three decades ago $^{4}$. Since then, numerous bis(crown-ethers) were obtained, in which they are linked to each other in various manners. Bis(crown-ethers) found numerous applications, e.g. in ion-selective electrodes ${ }^{5}$. In compounds of this type a great role is played the effect of cooperative behavior of both ether rings upon complexed cations. Different types of complexes formed between bis(crown-ethers) and cations are described in ${ }^{3}$.

Almost all crown ethers form complexes with alkali metal cations. These complexes often are formed between two molecules of crown-ether and one metal ion found sandwiched between the two rings of crown-ethers. Formation of such complexes and their potential applications led to the synthesis of many different bis(crown-ethers). Compounds of this kind often were more selective in complexing a given kind of ions compared to their mono analogues. There are two 
types of bis(crown-ethers) described in the literature: those based on benzo-crown-ethers and crown-ethers.

Among many bis(ether) compounds there are bis(crown-ethers) based on benzophenone ${ }^{6}$. They belong to the first kind of compounds mentioned above.

The present study describes synthesis of two bis(crown-ethers) 1 and 2 (Fig. 1), which belong to the second group of compounds. The synthetic procedure used two starting compounds which, presumably, would facilitate formation of sandwich-type complexes with alkali metals: 4,4'dihydroxybenzophenone and $\alpha, \alpha$ '-bis(para-hydroxyphenyl)-1,4-diisopropylbenzene. These compounds were used to obtain crown-ether derivatives. Structural formulas of compounds obtained are shown on Fig. 1.

Benzophenone is a good substrate for synthesis of sandwich-forming compounds. Aromatic rings rigidly bound via carbonyl bridge do not allow crown ethers to be separated significantly. This eases formation of intramolecular sandwich complexes with metal ions. In the case of the second starting compound two conformations of molecules are possible: syn and $a n t i^{7}$ (Scheme 1).

\section{Results and Discussion}

To synthesize bis(crown-ethers) 1 and 2, $\alpha, \alpha^{\prime}$-bis(para-hydroxyphenyl)-1,4-diisopropylbenzene obtained from phenol and 1,4-di(2-hydroxyprop-2-yl)benzene ${ }^{8}$ and 4,4'-dihydroxybenzophenone (commercially available) were used. The tosyloxymethyl derivative of the 15-crown-5-ether was synthesized from hydroxymethyl-15-crown-5 and p-toluenesulfonyl chloride according to the procedure described in the literature ${ }^{9,10}$. Condensation of hydroxyl derivatives and tosylated 15crown-5-carbinol proceeded for 3 days in $\mathrm{DMF}$ in the presence of $\mathrm{NaH}$ at $60^{\circ} \mathrm{C}$. The raw products $\mathbf{1}$ and $\mathbf{2}$ were purified by column chromatography on a silica gel with 72 and $37 \%$ yield, respectively.

Compounds 1 and 2 can form complexes of CE $\times$ Me type (CE denotes bis(crown-ether) and $\mathrm{Me}$ is alkali metal), as well as $\mathrm{CE} \times 2 \mathrm{Me}$. Owing to the lability of both ether rings also $2 \mathrm{CE} \times$ $\mathrm{Me}$ - type complexes are possible. All of the possible alkali metal ion complexes with the investigated crown ethers were confirmed using mass spectrometry (ESI MS). 

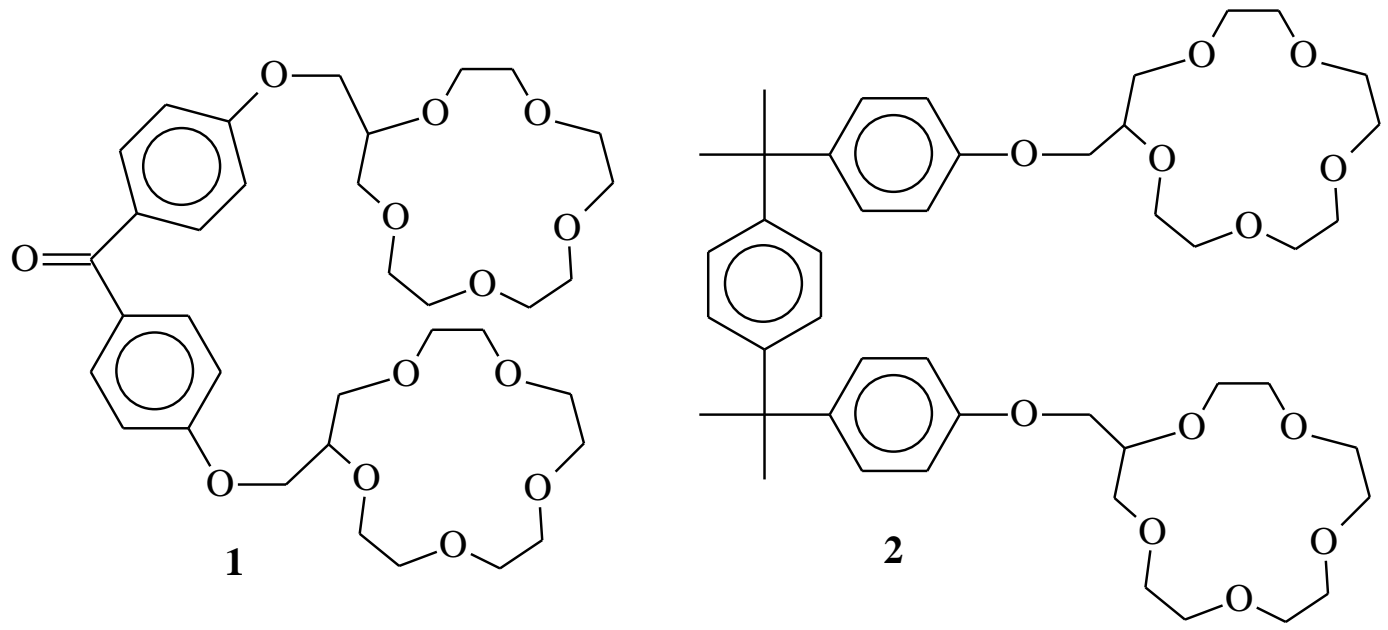

\section{Figure 1}

Compound 1, in which both crown ether rings are positioned closely to each other, forms with ions of sodium, rubidium and cesium strong complexes with apparent ESI MS molecular ion peaks of $100 \%$ intensity (see Table 1). The most intensive ion peak in the potassium complex 1 spectrum is the ion formed by two molecules of crown-ether and one potassium ion $(\mathrm{m} / \mathrm{z}=$ 1395). Lithium ions, owing to their small ionic radius form most frequently bimetallic complexes $\left([\mathbf{1}+2 \times \mathrm{Li}]^{+2}\right.$ and $[\mathbf{1}+\mathrm{Li}+\mathrm{LiI}]^{+}$, the intensity of which is $\left.100 \%\right)$. Bimetallic complexes are also formed by sodium and potassium ions. Peak intensity in ESI MS spectra for sodium ions depends on the accompanying anion. Particularly intensive ions are recorded for acetate anions. Ions with a larger ionic radius, such as rubidium and cesium tend to form monometallic complexes, albeit $2 \mathrm{CE} \times$ Me type ions were also observed. Bimetallic complexes for these ions are not observed. A much simpler situation occurs in the spectra of compound 2 complexes. From Table 2 it can be seen that peaks for $[\mathrm{CE}+2 \times \mathrm{Me}]^{+2}$ and $[2 \mathrm{CE}+\mathrm{Me}]^{+}-$type ions are observed only for lithium and sodium ions, i.e. those with smallest ionic radii. For these ions formation of bimetallic complexes is observed also but one metal ion is coupled to anion $\left(\mathrm{Li}^{+}\right.$with $\mathrm{I}^{-}$and $\mathrm{Na}^{+}$with $\mathrm{HCOO}^{-}$). Potassium forms complexes of all types considered here although the contribution of ions with $[2+2 \times \mathrm{K}]^{+2}$ and $[2 \times \mathbf{2}+\mathrm{K}]^{+}$structure in the spectrum is minor. In the spectra of rubidium and cesium complexes only one type of ions is observed, that of $[2+\mathrm{Me}]^{+}$(see scheme 1). This allows to assume that the formation of these complexes involves a cis conformer of compound 2. The trans conformer for rubidium and cesium ions should primarily give ion with $[2 \times \mathbf{2}+\mathrm{Me}]^{+}$or polymer - like structure.

UV spectrum of compound 1 has two almost identical bands: one at $\lambda=222 \mathrm{~nm}(\log \varepsilon=$ $4.17)$, and the other, long - wave, at $\lambda=293 \mathrm{~nm}(\log \varepsilon=4.31)$. The spectrum is almost identical with that of the model compound 4,4'-diethoxybenzophenone. The spectrum of this compound has also bands at 225 and $291 \mathrm{~nm}$ (cyclohexane solution), whereas in chloroform there is only 
one band at $\lambda=295.5$ ( $\log \varepsilon=4.37)$. Both spectra lack bands from $n \rightarrow \pi-$ type transitions, which in benzophenone occur at $\lambda=340 \mathrm{~nm}^{11}$.

UV spectra of compound 2 are characterized by the occurrence of three distinct bands at $\lambda=$ 240, 278 and $284 \mathrm{~nm}$ and the shoulder at $\lambda=270 \mathrm{~nm}$. These bands result from $\pi \rightarrow \pi^{*}-$ type transitions. There is no band above $300 \mathrm{~nm}$, i.e. a band resulting from $\mathrm{n} \rightarrow \pi$ - type transition.

In the IR spectrum of compound 1 there is a band at ca. $1645 \mathrm{~cm}^{-1}$, which may be ascribed to the $\mathrm{C}=\mathrm{O}$ fragment vibration. This band is red - shifted by $7 \mathrm{~cm}^{-1}$ compared to identical vibration in the model 4,4'-diethoxybenzophenone, and blue - shifted by $5 \mathrm{~cm}^{-1}$ compared to benzophenone 7. Vibrations characteristic for ether fragments $\left(v_{\mathrm{C}-\mathrm{O}-\mathrm{C}}\right)$ are very strong in the $1249-1251 \mathrm{~cm}^{-1}$ and $1119-1123 \mathrm{~cm}^{-1}$ ranges and strong in the $1032-1035 \mathrm{~cm}^{-1}$ range for both compounds (1 and 2). The remaining bands for both compounds $\mathbf{1}$ and $\mathbf{2}$ are given in the Experimental section.

Table 1. ESI mass spectra for mixture of 1 and alkali metals (Me). Diagnostic ions $(\mathrm{m} / \mathrm{z})$ and their abundance $(\%)$ in positive - ion experiment

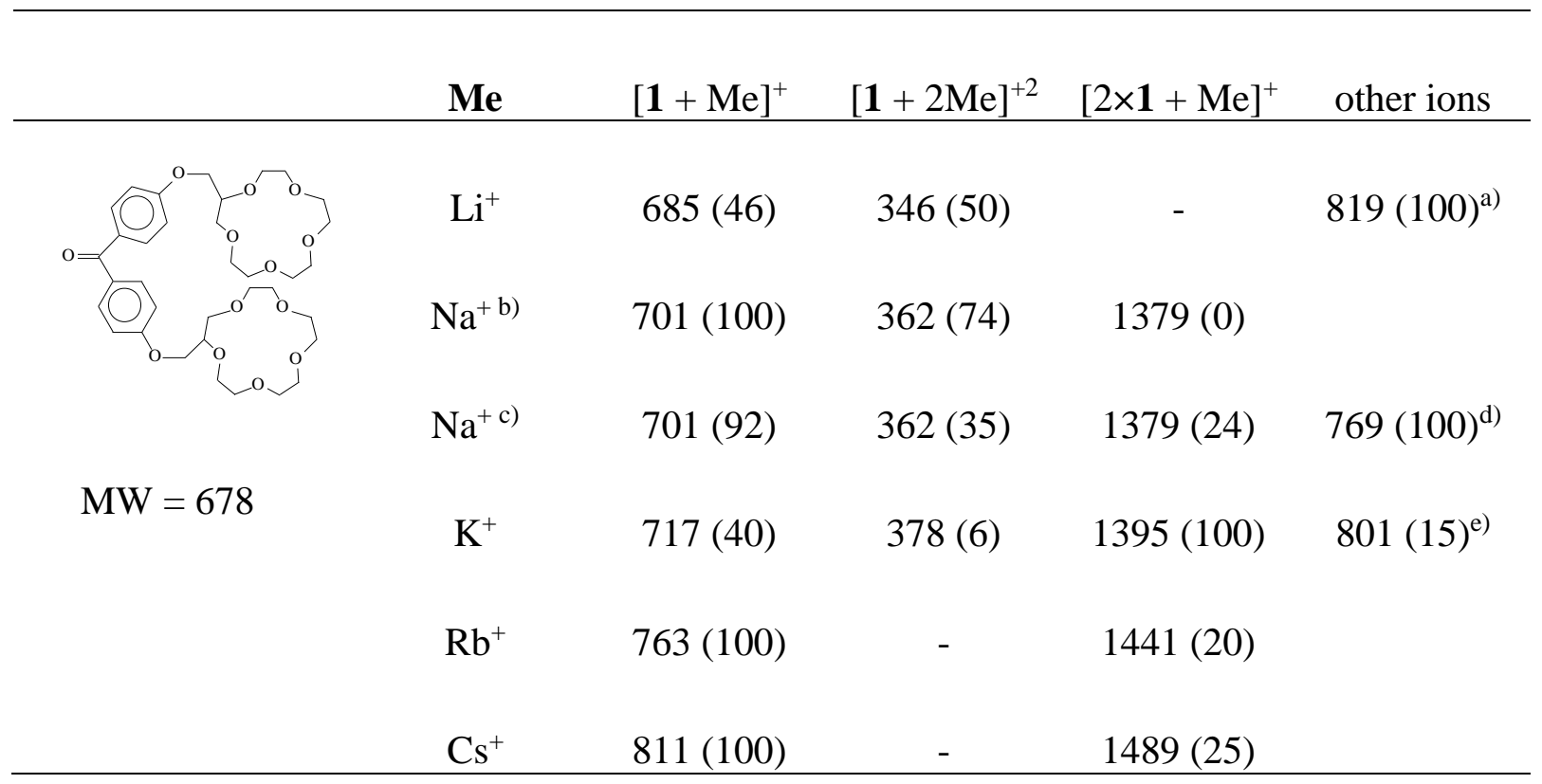

a) $[\mathbf{1}+\mathrm{Li}+\mathrm{LiI}]^{+}$; b) sodium formate; c) sodium acetate; d) $\left[\mathbf{1}+\mathrm{Na}+\mathrm{CH}_{3} \mathrm{COONa}\right]^{+}$; e) $[\mathbf{1}+\mathrm{K}$ $+\mathrm{HCOOK}]^{+}$ 
Table 2. ESI mass spectra for mixture of 2 and alkali metals (Me). Diagnostic ions (m/z) and their abundance $(\%)$ in positive - ion experiment

\begin{tabular}{|c|c|c|c|c|c|}
\hline & Me & {$[2+\mathrm{Me}]^{+}$} & {$[2+2 \mathrm{Me}]^{+2}$} & {$[2 \times \mathbf{2}+\mathrm{Me}]^{+}$} & other ions \\
\hline & $\mathrm{Li}^{+}$ & $817(5)$ & $412(72)$ & - & $951(100)^{a)}$ \\
\hline 2 & $\mathrm{Na}^{+}$ & $833(100)$ & $428(20)$ & $1643(2)$ & $901(70)^{b)}$ \\
\hline \multirow[t]{3}{*}{$\mathrm{MW}=810$} & $\mathrm{~K}^{+}$ & 849 (100) & $444(6)$ & $1659(6)$ & \\
\hline & $\mathrm{Rb}^{+}$ & 895 (100) & - & - & \\
\hline & $\mathrm{Cs}^{+}$ & $943(100)$ & - & - & \\
\hline
\end{tabular}

a) $[2+\mathrm{Li}+\mathrm{LiI}]^{+}$; b) $[2+\mathrm{Na}+\mathrm{HCOONa}]^{+}$

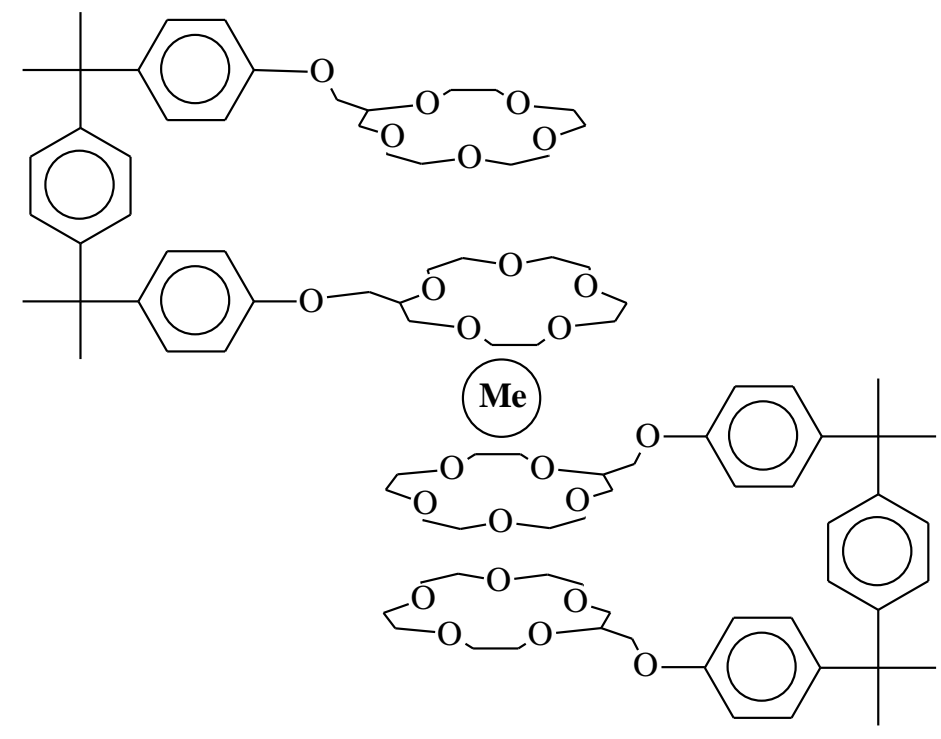

Scheme 1. Syn - form of 2 can form dimer - like complexes.

${ }^{1} \mathrm{H}$ NMR spectra shown in the experimental section have at the expected positions peaks due to aromatic protons. The signals of protons linking aromatic fragments with crown ethers occur at $\delta=4.00-4.20 \mathrm{ppm}$ for $\mathbf{1}$ and at $\delta=3.90-4.05 \mathrm{ppm}$ for $\mathbf{2}$ as multiplets. Among the remaining signals one might distinguish multiplets due to single protons attached to tertiary carbon atoms in ether fragments. The remaining peaks occur for both compounds as multiplets, at $\delta=3.40-3.80$ ppm. 


\section{Conclusions}

Two bis - crown ethers were obtained that can form complexes with alkali metal ions, at the ionization source of a mass spectrometer. For metal ions with lesser mass one can observe formation of various complexes with the investigated bis - ethers, whereas for rubidium and cesium ions preferential formation of bis - crown - ether / metal ion complexes is observed. In case of lithium, sodium and potassium ions formation of bimetallic complexes is observed. The obtained compounds belong to the group of ligand compounds in which particular fragments can cooperate with each other when forming complexes with metal ions.

\section{Experimental Section}

General. ${ }^{1} \mathrm{H}$ NMR spectra were recorded in $\mathrm{CDCl}_{3}$ or DMSO $-\mathrm{d}_{6}$ using a Bruker spectrometer $(500 \mathrm{MHz})$, with TMS as reference. UV spectra were recorded in methanol or chloroform solutions using Genesys 6 (ThermoSpectronic) spectrophotometer. IR spectra were recorded with the Nicolet FT - IR Magna 560 spectrometer. ESI MS experiments were performed on a LCQ DUO FINNINGAN THERMOQUEST instrument. The mixtures of the crowns and tenfold more concentrated alkali metal ions in chloroform - methanol solutions were directly injected into the ion sources using a syringe pump. Complex solutions were prepared directly before the analysis. Stock solutions of $\mathbf{1}$ and $\mathbf{2}$ were prepared by dissolving ca. $0.1 \mathrm{mmol}$ of each into $5 \mathrm{~mL}$ of chloroform - methanol $(3: 1, \mathrm{vol} / \mathrm{vol})$ mixture. $1 \mathrm{Mmol}$ alkali-metal salts (iodides or acetate) in methanol were prepared in each. $100 \mu \mathrm{L}$ aliquots of $\mathbf{1}$ or $\mathbf{2}$ were mixed with $100 \mu \mathrm{L}$ of cation solution and the obtained mixture was ten-fold diluted. 4,4'-Dihydroxybenzophenone was purchased from Aldrich. $\alpha, \alpha^{\prime}$-Bis(para-hydroxyphenyl)-1,4-diisopropylbenzene was synthesized according to ${ }^{8}$. Alkali metal salts were purchased from POCh (Poland) or Aldrich, and they were used as received.

Synthesis of 1: $0.53 \mathrm{~g}$ (2.5 mmol) of 4,4'-dihydroxybenzophenone, $2.01 \mathrm{~g}$ (5 mmol) tosyloxymethyl-15-crown-5, and $2 \mathrm{~g}$ of anhydrous $\mathrm{K}_{2} \mathrm{CO}_{3}$ were placed in a round - bottom flask containing $20 \mathrm{~mL}$ of DMF. The mixture was stirred at $60^{\circ} \mathrm{C}$ for 3 days. DMF was removed under reduced pressure and the residue was dissolved in water / dichloromethane mixture. Organic fraction was separated. Water fraction was extracted three times with dichloromethane. Combined organic fractions were washed with water (three times) and dried under anhydrous $\mathrm{MgCO}_{3}$. Purification was performed on alumina with ethyl acetate as eluent. The product was a yellow, sticky oil. Yield: $1.21 \mathrm{~g}(72 \%)$.

${ }^{1} \mathrm{H}$ NMR $\left(\mathrm{DMSO}-\mathrm{d}_{6}\right) ; \delta(\mathrm{ppm})=7.67,7.64(\mathrm{~d}, 4 \mathrm{H}, \mathrm{J}=8.8 \mathrm{~Hz}), 7.06,7.03(\mathrm{~d}, 4 \mathrm{H}, \mathrm{J}=8.8 \mathrm{~Hz})$, $4.20-4.00(\mathrm{~m}, 4 \mathrm{H}), 3.90-3.80(\mathrm{~m}, 2 \mathrm{H}), 3.78-3.40(\mathrm{~m}, 36 \mathrm{H})$.

${ }^{13} \mathrm{C}$ NMR $\left(\right.$ DMSO $\left.-\mathrm{d}_{6}\right) ; \delta(\mathrm{ppm})=193.7(\mathrm{C}=\mathrm{O}), 162.3,132.4,130.6,114.8$ (aromatic), 77.4, 70.6, 70.2, 69.9, 69.7, 68.7 (aliphatic). 
IR $\left(\mathrm{cm}^{-1}\right)$ : 3068w, 3044w, 2870vs, 2744sh, 1645vs, 1600vs, 1574w, 1509vs, 1455s, 1419s, $1383 \mathrm{w}, 1350 \mathrm{~s}, 1304 \mathrm{~s}, 1285 \mathrm{~s}, 1251 \mathrm{vs}, 1169 \mathrm{~s}, 1135 \mathrm{vs}, 1032 \mathrm{~s}, 987 \mathrm{w}, 951 \mathrm{sh}, 928 \mathrm{~s}, 852 \mathrm{~s}, 770 \mathrm{~s}$, $731 \mathrm{w}, 686 \mathrm{~s}, 652 \mathrm{w}, 623 \mathrm{~s}, 602 \mathrm{w}, 509 \mathrm{w}$.

UV (metanol); $\lambda(\mathrm{nm}, \log \varepsilon)=293$ (4.31), 222 (4.17).

ESI MS (m/z): $679(\mathrm{M}+\mathrm{H})^{+} ; 701(\mathrm{M}+\mathrm{Na})^{+} ; 1379(2 \mathrm{M}+\mathrm{Na})^{+} ; 362(\mathrm{M}+2 \mathrm{Na})^{+2}$.

Anal.Calcd for $\mathrm{C}_{35} \mathrm{H}_{50} \mathrm{O}_{13}: \mathrm{C}, 61.93 ; \mathrm{H}, 7.42$. Found: $\mathrm{C}, 61.78 ; \mathrm{H}, 7.47$.

Synthesis of 2: 1.73g (5mmol) $\alpha, \alpha^{\prime}$-bis(para-hydroxyphenyl)-1,4-diisopropylbenzene, 4.04g (10mmol) tosyloxymethyl-15-crown-5 and $2.3 \mathrm{~g}$ of anhydrous potassium carbonate were placed in a flask containing $30 \mathrm{~mL}$ of DMF. The mixture was stirred at $60^{\circ} \mathrm{C}$ for three days. DMF was removed under reduced pressure. The residue was dissolved in the water - dichloromethane mixture. Organic fractions were washed with water (5 times), dried and evaporated. Purification was performed on silica gel with ethyl acetate as eluent. Product was crystallized as white powder from methanol. Yield: $1.5 \mathrm{~g}(37 \%)$. M.p. $102-104{ }^{\circ} \mathrm{C}$.

${ }^{1} \mathrm{H} \mathrm{NMR}\left(\mathrm{CDCl}_{3}\right) ; \delta(\mathrm{ppm})=7.14,7.11(\mathrm{~d}, 4 \mathrm{H}, \mathrm{J}=8.7 \mathrm{~Hz}), 7.08(\mathrm{~s}, 4 \mathrm{H}), 6.82,6.79(\mathrm{~d}, 4 \mathrm{H}, \mathrm{J}=$ $8.7 \mathrm{~Hz}), 4.05-3.90(\mathrm{~m}, 4 \mathrm{H}), 3.90-3.80(\mathrm{~m}, 2 \mathrm{H}), 3.80-3.60(\mathrm{~m}, 36 \mathrm{H}), 1.62(\mathrm{~s}, 12 \mathrm{H})$.

${ }^{13} \mathrm{C} \mathrm{NMR}\left(\mathrm{CDCl}_{3}\right) ; \delta(\mathrm{ppm})=157.0,148.3,143.5,128.1,126.6$ (aromatic), 78.5, 71.6, 71.5, $71.3,71.2,71.0,70.9,70.8,42.3,31.39$ (aliphatic).

IR $\left(\mathrm{cm}^{-1}\right)$ : 3048w, 2963s, 2912s, 2870vs, 1608w, 1580w, 1509w, 1462s, 1453s, 1400w, 1383w, 1356s, 1293s, 1249vs, 1184s, 1119vs, 1035w, 1012w, 936w, 831s.

UV (metanol); $\lambda(\mathrm{nm}, \log \varepsilon)=233$ (4.34), 270sh (3.64), 276 (3.73), 283 (3.63).

(chloroform); $\lambda(\mathrm{nm}, \log \varepsilon)=241$ (3.97), 267sh (3.48), 278 (3.64), 284 (3.55).

ESI MS (m/z): $833(\mathrm{M}+\mathrm{Na})^{+}, 428(\mathrm{M}+2 \mathrm{Na})^{+2}$.

Anal.Calcd for $\mathrm{C}_{46} \mathrm{H}_{66} \mathrm{O}_{12}$ : C, 68.12; H, 8.20. Found: C, 67.70; H, 8.01.

\section{References}

1. An, H.; Bradshaw, J. S.; Izatt, R. M.; Yan, Z. Chem. Rev. 1994, 94, 939.

2. Krakowiak, K. E.; Bradshaw, J. S.; Zamecka-Krakowiak, D. J. Chem.Rev. 1989, 89, 929.

3. Fery-Forgues, S.; Al-Ali, F. J.Photochem.Photobiol. C: Photochem. Rev. 2004, 5, 139.

4. Wong, K. H.; Bourgoin, M.; Smith, J. Chem.Commun. 1974, 715.

5. Oggenfuss, P.; Morf, W.E.; Oesch, U.; Ammann, D.; Pretsch, E.; Simon, W. Anal.Chim. Acta. 1986,180, 299.

6. Huang, S.; Yuan, L.-H.; Tian, B.-Z.; Jiang, Y.-W. Youji Huaxue 1991, 470.

7. Kuś, P.; Jones, P. G. Z.Naturforsch. 2004, 59b, 1026.

8. Broderick, G. F.; Oxenrider, B. C.; Vitrone, J. U.S.Patent 33932441968.

9. Ouchi, M.; Inoue, Y.; Liu, Y.; Nagamune, S.; Nakamura, S.; Wada, K.; Hakushi, K. Bull.Chem.Soc.Jpn. 1990, 63, 1260.

10. Czech, B.; Son, B.; Bartsch, R.A. Tetrahedron Lett. 1983, 24, 2923.

11. Kuś, P.; Jones, P. G. Polish J.Chem. 2000, 74, 965. 